\title{
LOSS OF A LEADING LIGHT: A TRIBUTE TO THE LATE THEODORE H 'TED' MAIMAN
}

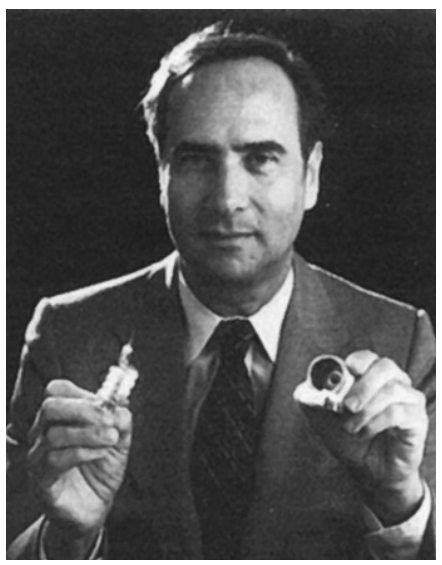

Fig. 1: Ted Maiman displaying the components of the first laser: the ruby rod within the helical flashlamp in his right hand, and the machined cylinder in his left.

Before launching into the main subject of this Editorial, I should just like to note in passing that the $2^{\text {nd }}$ congress of the International Phototherapy Association (IPTA) was held successfully in New Zealand at the end of April. If you were not there, you missed a great meeting, and I would like to congratulate Professor David Baxter, Dean of the Faculty of Physiotherapy at Otago University, for his tremendous work which resulted in the success which the meeting undoubtedly was. A full report on the meeting will appear in a future issue of this journal.

The Editorial in 17.1 recognised the tremendous influence of the "Father of Phototherapy", the late Prof. Endré Mester, on our particular field of interest. In this current issue, I should like to pay tribute to, and salute the man I would like to call the 'Father of All Lasers', Ted Maiman, who died just over one year ago on May $5^{\text {th }}, 2007$ at the age of 79. Although famous worldwide for his successful development of the first working laser in 1960, Ted considered himself first and foremost a scientist and an engineer, but with strong research interests in electro-optics, lasers, and aerodynamics. Hailed by some as the "father of the electrooptics industry", Ted Maiman remained, however, to the end a humble and self-effacing gentleman.

Born in Los Angeles, California, on July $11^{\text {th }}$, 1927, but raised in Denver, Colorado, Ted developed an early interest in things technological, inspired by his father Abraham, himself an inventor and electronics engineer. Ted worked part-time in his teenage years as an electrical repair man, working on radios and other electrical appliances, and then went on to study physics and electrical engineering at the University of Colorado at Boulder from which he graduated in 1949. He then went to Stanford University, Palo Alto, where he took a masters degree in electrical engineering in 1951 and $\mathrm{a} \mathrm{PhD}$ in physics in 1955. His mentor there was Willis E Lamb, who became the Nobel Laureate in Physics also in 1955.

Forsaking the 'staid halls of academe', Maiman instead entered the very exciting field of practical research, and took up a post with the Hughes Aircraft Company owned by the eccentric, reclusive billionaire Howard Hughes, and which was a real melting pot of technological excellence staffed with brilliant and often very colourful scientists and researchers. In the late 50's, the MASER (microwave amplification by stimulated emission of radiation) was the thing of wonder, and with working masers weighing in at more than 2 tonnes, Maiman was tasked with developing a more compact maser based on microwave emission from chromium atoms in synthetic ruby crystals as the medium. Ted's new design of maser weighed in at $2 \mathrm{~kg}$ with equal if not better efficacy. However, his work with the synthetic chromium-doped ruby crystal was to very useful in couple of years' time. 
The basic operating principles of a device based on LIGHT amplification by stimulated emission of radiation, i.e., the laser (to use the name first given to it by Gould), were first postulated by Nobel Laureates Charles Townes and Arthur Schalow from the Bell Telephone Laboratories in 1958, in what they referred to as an 'optical maser', and the race to develop such a system was on with a vengeance. Almost all of the researchers, working in geographical locations as diverse as the USA, UK and Russia, were concentrating on gases as the laser medium, but Maiman accepted the challenge in 1959 and unlike the others, believed that the doped synthetic ruby crystal, the medium of his maser, was a viable medium, provided he could find a light source bright enough to pump the crystal with enough energy to achieve population inversion, the state when more of the electrons in the medium are in an excited state than in the ground resting state, and the prerequisite to laser emission. Maiman first tried to achieve this with the most powerful cinema projector lamps available, but was able to produce only a glow in the target crystal and not the intense output of coherent light at the ruby line he was hoping for. One Maiman's research students, Charles Asawa, suggested using a helical photographic flashlamp. Ted seized upon this idea, and constructed a device with a small, finger-sized ruby crystal both ends of which were silvered, and then one was lightly scratched to allow the emission of light. The crystal was surrounded by the flashlamp, both of which were physically small as illustrated in Figure 1 of Maiman himself. The crystal and flashlamp were sealed inside a machined and polished aluminium cylinder, and on May $16^{\text {th }} 1960$, when he powered the flashlamp with more and more powerful electrical charges, the rod produced ever and ever brighter flashes of intense red light until finally a short pulse of true laser energy was generated at the correct line, or wavelength, satisfying the criterion for stimulated emission of visible radiation, and the race to produce the first laser was won by Maiman after months of intense effort. Although the physical size of the components was very small, the intensity of the light was greater, point for point, than the sun itself. Sad to note, Ted died within days of the $48^{\text {th }}$ anniversary of his epoch-making discovery.

Maiman submitted his research as a paper to the prestigious US journal, Physical Review Letters, which summarily rejected it. Maiman's second choice, the equally prestigious British journal Nature, accepted the paper, so ironically a truly American discovery was first reported in a British journal. ${ }^{(1)}$ In the meantime, Bell Laboratories attempted to circumvent Maiman's rightful place as the 'inventor' of the first laser by somehow persuading Physical Review Letters to publish a report on their own copy-cat version without acknowledging the vast majority of Maiman's work. That body of work has more than stood the test of time, however, although he never forgot or forgave Bell Labs for their 'dirty tricks' (Ted's own words) which he wrote about in some detail in his very interesting and outspoken autobiography, The Laser Odyssey, in which he quite happily describes his "maverick spirit" which helped him win the laser race. ${ }^{(2)}$

Maiman then went on to found the Korad Corporation, producing ruby and other lasers, which was eventually bought over in 1968 by Union Carbide. Ted then went on to found Maiman Associates, and for a while was a director of Control Laser Corporation. The author feels very close to Ted Maiman, as the author was the first in Japan to purchase and import in 1976 a Korad industrial ruby laser into Japan, which the author then modified to produce the homogeneous beam required for medical applications. This was a large system, which we called 'The Canon', the reason for which can be seen in Fig. 2. Thereafter, in 1979, the author added a Control Systems Nd:YAG laser to his armamentarium, again a modified industrial system, which was one of the first lasers in Japan and indeed internationally to be remotely situated from the treatment rooms, with fibreoptic delivery systems and a complete remote control panel.

In honour of Maiman's achievements, he received two nominations for the Nobel Prize, sadly unsuccessful. In the author's humble opinion, he should have been a Nobel Laureate along with Schalow and Townes. Ted was successfully nominated for Membership of the US National Academy of Science and the National Academy of Engineering; he became a Fellow of the American Physical Society; he was

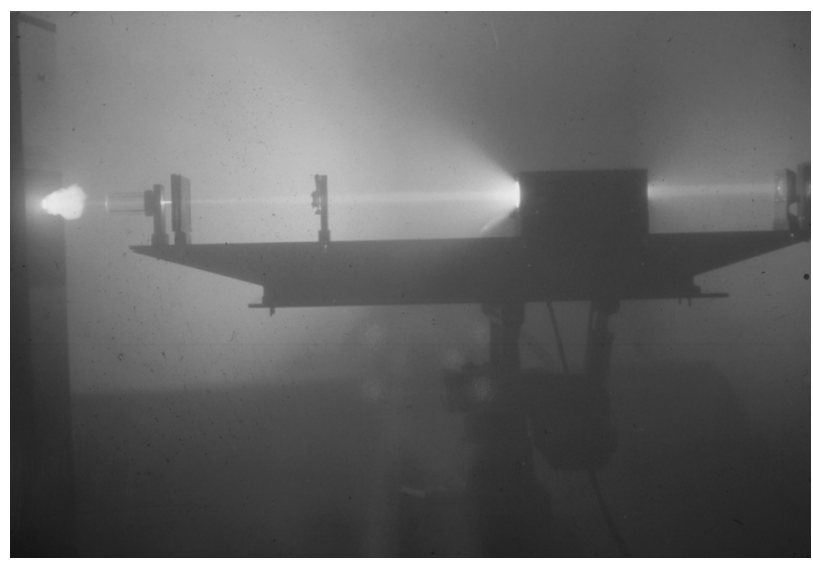

Fig. 2: Luby Laser 


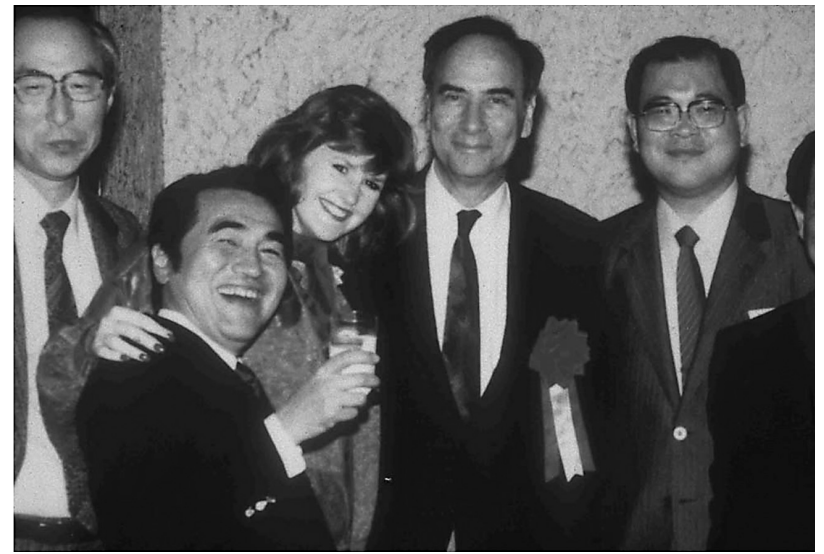

Fig. 3: Two persons in the middle are Ted and Kathleen Maiman at International Society for Nd:YAG Laser.

awarded the Hertz Prize for Physics, presented by then-President Lyndon B Johnson in a White House ceremony; he was awarded the 1983/84 Wolf Prize in Physics, and was inducted into the National Inventors' Hall of Fame in 1984. The Royal College of Surgeons of England also accepted him as an Honorary Fellow. As many great scientists and inventors, including fellow Hall of Fame inductee Thomas Alva Edison, would agree, serendipity can be one of the greatest influences

\section{References}

1: Maiman TH: Stimulated Optical Radiation in Ruby. Nature 187, 493-494, 1960. in any scientist's life: it was while Ted was on the way home from the Hall of Fame induction ceremony in 1984 that he met the lovely Kathleen, who would become his second wife, and whom he would have happily agreed was his greatest discovery of all.

Another of his most prestigious awards was the Japan Prize, awarded in 1987. This is the Asian equivalent of the Nobel Prize, and is dignified by the Emperor of Japan. It was while visiting Japan to receive this prestigious award that the Author had the honour and pleasure of meeting both Ted and Kathleen Maiman personally, at a special reception hosted in the Maimans' honour by the International Society for Nd:YAG Laser which started a long-term friendship, and Fig. 3 shows us all together at that special reception.

While we may mourn the loss of the man, his invention lives on in all walks of our life, with surgical and therapeutic lasers, CD-ROM and DVD players and readers/writers, and even the ubiquitous supermarket scanner. He is survived by all these, and also by his wife Kathleen and a daughter. Ted, we at Laser Therapy are proud to salute the memory of a true gentleman, scientist, researcher, scholar and "maverick spirit".

Tokyo, May,2008

Toshio Ohshiro

2: Maiman TH: The Laser Odyssey: Laser Press, October 2000, Vancouver, Canada. 